\title{
Assessment of Reliability when Using Diagnostic Binary Ratios of Polycyclic Aromatic Hydrocarbons in Ambient Air PM
}

\author{
Siwatt Pongpiachan
}

\begin{abstract}
The reliability of using diagnostic binary ratios of particulate carcinogenic polycyclic aromatic hydrocarbons (PAHs) as chemical tracers for source characterisation was assessed by collecting PM10 samples from various air quality observatory sites in Thailand. The major objectives of this research were to evaluate the effects of day and night on the alterations of six different PAH diagnostic binary ratios: An/(An + Phe), Fluo/(Fluo + Pyr), B[a]A/(B[a]A + Chry), B[a]P/(B[a]P + B[e]P), Ind/(Ind + B[g,h,i]P), and B[k]F/Ind, and to investigate the impacts of site-specific conditions on the alterations of PAH diagnostic binary ratios by applying the concept of the coefficient of divergence (COD). No significant differences between day and night were found for any of the diagnostic binary ratios of PAHs, which indicates that the photodecomposition process is of minor importance in terms of PAH reduction. Interestingly, comparatively high values of COD for An/(An + Phe) in PM10 collected from sites with heavy traffic and in residential zones underline the influence of heterogeneous reactions triggered by oxidising gaseous species from vehicular exhausts. Therefore, special attention must be paid when interpreting the data of these diagnostic binary ratios, particularly for cases of low-molecular-weight PAHs.
\end{abstract}

Keywords: Diagnostic binary ratios - PAHs - photolysis - spatial distribution

Asian Pac J Cancer Prev, 16 (18), 8605-8611

\section{Introduction}

Over recent decades, major advances have been made in elucidating the environmental fate and behaviour of polycyclic aromatic hydrocarbons (PAHs) in various environmental situations (Pongpiachan, 2013a,b, 2014, 2015; Pongpiachan et al., 2013a,b,c, 2015a,b). The principal reasons for investigating environmental concentrations of PAHs relate to their adverse effects on health, such as their potential to disrupt the endocrine system (Annamalai and Namasivayam, 2015), increase anxiety-related behaviour and decrease regional brain metabolism in adult male rats (Crépeaux et al., 2012), and cause adverse reproductive outcomes (Šrám et al., 1999), DNA damage to lungs (Müller et al., 2004), the development of solid tumours in mice (Wang and Xue, 2015), and increased risks of coupled lung and breast cancers (Venkatachalam et al., 2014; Moorthy et al., 2015). As a consequence of the numerous adverse health effects, several studies have used receptor models, including principal component analysis (Pongpiachan, 2013b), positive matrix factorisation (Jang et al., 2013), and a chemical mass balance model (Hanedar et al., 2011), to quantitatively identify potential sources of atmospheric PAHs.

Selecting one among the many source-apportionment models is undoubtedly an important and difficult task because of the requirements for specific skill, knowledge, and experience. Conversely, the application of diagnostic binary ratios of PAH congeners to categorise their potential sources is a comparatively simple process, which provides a broad comprehensive perspective of source classification. For these particular reasons, diagnostic binary ratios of PAHs have been used widely as promising chemical tracers in marine deposits, terrestrial soils, atmospheric particles, and agricultural products (Tipmanee et al., 2012; Alam et al., 2013; Pongpiachan, 2014, 2015; Pongpiachan et al., 2015a,b).

Despite their capability in classifying emission source types, some ambiguities remain regarding the reliability of diagnostic binary ratios of PAHs. Generally, the vast majority of studies associated with the application of PAH binary ratios have paid little attention to adsorption, volatilisation, photolysis, and chemical and microbial degradation, which can selectively decrease the atmospheric contents of low-molecular-weight (LMW) PAHs in comparison with those of high-molecular-weight (HMW) congeners. Previous studies have highlighted the importance of meteorological parameters (e.g., ambient temperature and relative humidity), sub-cooled liquid vapour pressures $\left(\mathrm{p}^{\circ} \mathrm{L}\right)$, the octanol-air partitioning coefficient (KOA), and the soot-air partitioning coefficient

NIDA Center for Research \& Development of Disaster Prevention \& Management, School of Social and Environmental Development, National Institute of Development Administration (NIDA), Sereethai Road, Bangkapi, Bangkok, Thailand *For correspondence: pongpiajun@gmail.com 
(KSA) on the gas-particle partitioning coefficient of PAHs (Dachs and Eisenreich, 2000; Odabasi et al., 2006; Pongpiachan, 2010; Pongpiachan et al., 2010, 2013b; Wang et al., 2013). According to Gao et al. (2015), gas-particle partitioning can play a significant role in estimations of the source apportionment of atmospheric PAHs and their toxicity using positive matrix factorisation. Furthermore, PAHs can be degraded by sulphate anion radicals in atmospheric aqueous droplets (Wang et al., 2008) as well as by photo-decomposition by UV light (Wang et al., 2005) coupled with both homogeneous and heterogeneous chemical reactions with atmospheric oxidants (Ringuet et al., 2012a; Zhang et al., 2013).

Although several factors can dramatically affect the reduction of each $\mathrm{PAH}$ congener with different magnitudes, little is known about the reliability of using their binary ratios as chemical tracers of emission sources, particularly in the tropical atmosphere. One of the many crucial aspects of the current study concerned the effects of day and night on the variations of diagnostic binary ratios of $\mathrm{PM}_{10}$-bounded PAHs collected from three different cities in Thailand. During the past few years, numerous studies have investigated the impact of diurnal variations on the fluctuation of atmospheric contents of PAHs (Ringuet et al., 2012b; Liu et al., 2013; Ohura et al., 2013) but none has examined the impacts of day and night on the alteration of their binary ratios. Furthermore, the influence of sampling site on the fluctuation of each PAH diagnostic binary ratio remains unclear and its elucidation is critical. Overall, the principal objectives of this study were $(i)$ to investigate the impacts of day and night on the variation of PAH diagnostic binary ratios, including anthracene and phenanthrene $(\mathrm{An} /(\mathrm{An}+\mathrm{Phe}))$, fluoranthene and pyrene (Fluo/(Fluo + Pyr)), benzo[a]anthracene and chrysene $(\mathrm{B}[\mathrm{a}] \mathrm{A} /(\mathrm{B}[\mathrm{a}] \mathrm{A}+\mathrm{Chry}))$, benzo[a]pyrene and benzo[e] pyrene $(\mathrm{B}[\mathrm{a}] \mathrm{P} /(\mathrm{B}[\mathrm{a}] \mathrm{P}+\mathrm{B}[\mathrm{e}] \mathrm{P}))$, indeno[1,2,3,-c,d] pyrene and benzo $[g, h, i]$ perylene (Ind/(Ind $+\mathrm{B}[g, h, i] \mathrm{P})$ ), and benzo[k]fluoranthene and indeno[1,2,3,-c,d]pyrene $(\mathrm{B}[\mathrm{k}] \mathrm{F} / \mathrm{Ind})$, and (ii) to assess the influence of air quality observatory sites on the fluctuation of PAH diagnostic binary ratios; specifically, An/(An + Phe) and Fluo/(Fluo + Pyr). In addition, in the current paper, the concept of the coefficient of divergence (COD) is introduced and discussed further.

\section{Materials and Methods}

Description of air quality observatory sites and $P M_{10}$ sample collection

The monitoring campaign adopted in this study can be broadly categorised into three sections. Firstly, the Spatial Distributions of $\mathrm{PM}_{10}$-bounded PAHs based on a Monitoring Campaign (SDPMC) were carefully assessed using seven air quality monitoring sites operated by the Pollution Control Department of the Ministry of Natural Resources and Environment, Thailand: Klongchan National Housing Authority (KHA; 1349'11.761”N, 100³4'33.190”'E), Nonsreewitayakom High School (NWS; 1342’28.937'N, 100³2'50.443’'E), Singharaj Pitayakhom High School (SPS), Thonburi Power Substation (TPS; 1343’39.205”N, 100²9'11.776”E),

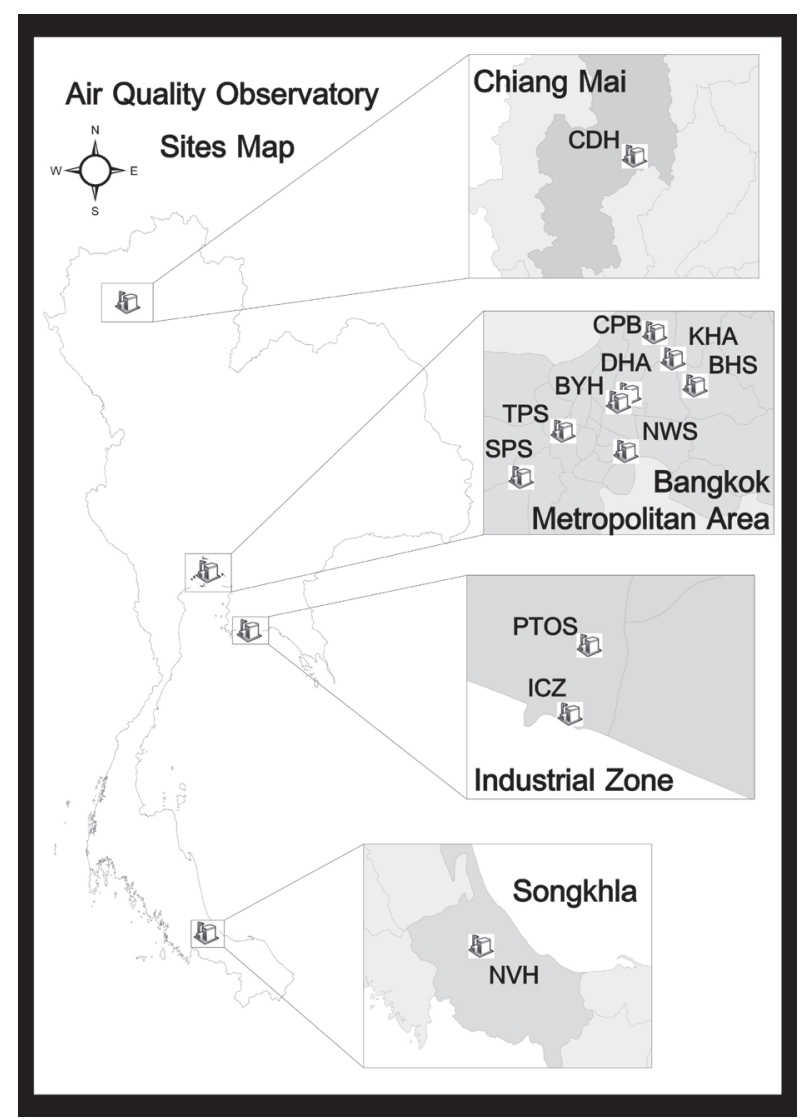

Figure 1. Map of Air Quality Observatory Sites in this Study

Chokchai 4 Police Box (CPB; 1347'33.474”N, $\left.100^{\circ} 35^{\prime} 45.879^{\prime} \mathrm{E}\right)$, Dindang National Housing Authority (DHA; 1346'59.544”N, 100³2'25.618”E), and Badindecha High School (BHS; $13^{\circ} 46^{\prime} 10.745^{\prime}$ N, $100^{\circ} 36$ '52.433'E) (see Figure 1). It should be noted that sites CPB, KHA, and DHA were situated adjacent to traffic routes, reflecting PAH emissions from vehicular exhausts, whilst sites NWS, SPS, TPS, and BHS, located in residential areas, reflected residential background PAH emissions. Air quality observation campaigns were conducted concurrently at all monitoring sites on a normal weekday every month from January 2006 to December 2006, which provided a database of 84 individual $\mathrm{PM}_{10}$ samples (i.e., $12 \times 7=84$ ).

Secondly, the Diurnal variations of $\mathrm{PM}_{10}$-bounded PAHs based on an Intensive Monitoring Campaign (DPIMC) were prudently chosen using three different air quality monitoring sites: the Baiyoke Suite Hotel (BYH: 1345'10.65”N, 100³2'24.92”E), Centara Duangtawan Hotel (CDH: 1847'03.46”N, 9859'56.72”E), and Novotel Centara Hat-Yai Hotel (NVH: $7^{\circ} 00^{\prime} 20.65$ 'N, $\left.100^{\circ} 28^{\prime} 15.65^{\prime} \mathrm{E}\right)$, as clearly illustrated in Figure 1 . It is worth mentioning that $\mathrm{BYH}, \mathrm{CDH}$, and $\mathrm{NVH}$ are located in the city centre of Bangkok, Chiang-Mai, and Hat-Yai, respectively. In the case of $\mathrm{BYH}, \mathrm{PM}_{10}$ samples were collected every three hours consecutively from 21:00 local time (LT) 18 February to 21:00 LT 21 February 2008 , whilst those of CDH were sampled every three hours sequentially from 21:00 LT 25 February to 21:00 LT 28 February 2008. In addition, the variations of $\mathrm{PM}_{10}{ }^{-}$ bounded PAHs were measured at NVH every three hours consecutively from 21:00 LT 17 December to 21:00 LT 20 
Assessment of Reliability when Using Diagnostic Binary Ratios of Polycyclic Aromatic Hydrocarbons in Ambient Air PM10

December 2007. These measurements provided a database of 72 individual $\mathrm{PM}_{10}$ samples (i.e., $8 \times 3 \times 3=72$ ).

Thirdly, Concurrent Monitoring of $\mathrm{PM}_{10}$-bounded PAHs in Industrial Areas (CMPIA) was performed at the Pluakgate Temple Observatory Station (PTOS) (12 39'41.70”N, $101^{\circ} 18^{\prime} 53.62$ 'E) and IRPC Complex Zone Observatory Station (ICZOS) (12³9'10.46”N, $\left.101^{\circ} 18^{\prime} 7.66^{\prime \prime} \mathrm{E}\right)$. The PTOS is situated within a petrochemical industrial area of Tumbol Cherngnern, Muang District in Rayong Province, which is located approximately $1.2 \mathrm{~km}$ northeast of the IRPC refineries (Figure 1). The ICZOS (12³9'10.46”N, 101¹8'7.66”E) was chosen because of its proximity to the IRPC seaport (i.e., a distance of approximately $1.4 \mathrm{~km}$ ), meaning that it could be considered representative of a mixture of shipping and industrial emissions. Graseby-Anderson (TE-6001) high volume air samplers were used to achieve unmanned 24-h and 3-h samplings of $\mathrm{PM}_{10}$ for SDPMC coupled with CMPIA and DPIMC, respectively. Samples of $\mathrm{PM}_{10}$ were collected on $20 \times 25 \mathrm{~cm}$ Whatman glass fibre filters under an airflow rate of about $1.133 \mathrm{~m} 3 \mathrm{~min}$ 1 (i.e., $40 \mathrm{cfm}$ ). A comprehensive explanation of the air sampling method is given in "Compendium Method IO2.2. Sampling of Ambient Air for $\mathrm{PM}_{10}$ using an Andersen Dichotomous Sampler" (US-EPA, 1999). Samples of total ambient $\mathrm{PM}_{10}$ from both PTOS and ICZOS were collected on 75 days in discontinuous sequences from 1-10 February $2010(\mathrm{n}=10), 19-28$ April $2011(\mathrm{n}=10), 5-14$ March 2012 $(\mathrm{n}=10), 27-31$ October $2012(\mathrm{n}=5), 22-31$ March 2013 $(n=10)$, and 7 June to 6 July $2013(n=30)$. Samples of $\mathrm{PM}_{10}$ were collected simultaneously at both sites for $24 \mathrm{~h}$ every day from 09:00 LT to 09:00 LT on the following day. These observations provided a database of 150 individual $\mathrm{PM}_{10}$ samples (i.e., $75 \times 2=150$ ).

\section{Analysis of PAHs}

All organic solvents (i.e., dichloromethane and hexane) were HPLC grade, purchased from Fisher Scientific. A cocktail of 11 PAHs to Norwegian Standard NS 9815: S-4008-100-T (phenanthrene (Phe), anthracene (An), fluoranthene (Fluo), pyrene (Pyr), benz[a]anthracene (B[a]A), chrysene (Chry), benzo[k]fluoranthene $(\mathrm{B}[\mathrm{k}]$ $\mathrm{F})$, benzo[a]pyrene $(\mathrm{B}[\mathrm{a}] \mathrm{P})$, benzo[e]pyrene $(\mathrm{B}[\mathrm{e}] \mathrm{P})$, indeno[1,2,3-c,d]pyrene (Ind), and benzo[g,h,i]perylene $(\mathrm{B}[\mathrm{g}, \mathrm{h}, \mathrm{i}] \mathrm{P})$; each $100 \mu \mathrm{g} \mathrm{mL}-1$ in toluene: unit: $1 \times 1$ $\mathrm{mL})$ and a mixture of recovery Internal Standard PAHs $\left(\mathrm{d}_{12}\right.$-perylene $\left(\mathrm{d}_{12}\right.$-Per $), \mathrm{d}_{10}$-fluorene $(\mathrm{d} 10-\mathrm{Fl})$; each $100 \mu \mathrm{g}$ mL-1 in xylene: unit: $1 \times 1 \mathrm{~mL}$ ) were supplied by Chiron AS (Stiklestadveine 1, N-7041 Trondheim, Norway). Standard stock solutions of $4 \mu \mathrm{g} \mathrm{mL}{ }^{-1}$ of deuterated PAHs (used as internal standards) and $100 \mu \mathrm{g} \mathrm{mL}-1$ of native PAHs were prepared in nonane. The dilution of the working standards was conducted using n-cyclohexane. A half-cut sample of the glass fibre filter was transferred to a $250 \mathrm{~mL}$ Soxhlet extractor and then $50 \mu \mathrm{L}$ of d12-Per and d10-Fl was spiked to the glass fibre filter sample as an internal standard. These samples were treated in 200 $\mathrm{mL}$ of dichloromethane for $8 \mathrm{~h}$ in a Soxhlet extractor, following which solvent removal was conducted using a nitrogen blow-down evaporator.

The glass container was washed repeatedly with hexane and the fractionation/clean-up and blow-down processes adhered strictly to the method suggested by Gogou et al. (1996). The congeners and concentrations of PAHs were both qualitatively and quantitatively analysed using GC/MS (Varian Saturn 2000 GC/MS) installed with a fused silica capillary column $(60-\mathrm{m}$ length $\times 0.25-\mathrm{mm}$ i.d. of DB5 capillary column coated with a $0.25-\mu \mathrm{m}-$ thickness film) and a Saturn workstation program. Highpurity He gas $(99.99 \%)$ was used as the carrier gas. The GC temperature programming and the quantification and identification of the congeners are clearly explained in Pongpiachan et al. (2009). Quality assurance and quality control were evaluated using the standard SRM 1941b. Mean recovery (based on the extraction of matrix-matched certified reference materials, $(n=8)$ was within the range $77-119 \%$. The precision of the analytical method, computed as the relative standard deviation on the duplicate samples, was $<15 \%$. All PAH concentrations were quantified using standardised relative response factors run with each batch (Pongpiachan et al., 2009).

\section{Statistical analysis}

As a part of the effort to assess the reliability of using diagnostic binary ratios of PAHs as chemical tracers, the arithmetic mean, standard deviation, $t$-Test, and analysis of variance were calculated using statistical software (SPSS v.13.0; SPSS Inc., Chicago, IL, USA).

\section{Results and Discussion}

Effects of photolysis on variations of diagnostic binary ratios of PAHs

Photolysis is the main process that influences the residence time and behaviour of atmospheric particulate PAHs, both in the atmosphere and after wet/dry deposition. A study by Kim et al. (2013) highlighted the importance of both fast photodegradation and fast diffusion kinetics on the reduction of LMW PAHs (with 2-3 rings) in comparison with HMW PAHs (with 4 or more rings). Although the photodegradation rates of 16 U.S. EPA-priority PAHs follow first-order kinetics, UV-B (315-280 nm) exposure can dramatically accelerate the photolysis rate of PAHs adsorbed onto fly ash particles (Niu et al., 2007). However, this is not the case for the photodecomposition of PAHs at ground level, because the majority of UV-B radiation is absorbed by the ozone layer in the stratosphere (Caldwell and Flint, 1994). As illustrated in Table 1, no significant differences between day and night were found for any of the diagnostic binary ratios of PAHs, irrespective of differences in their source emission characteristics, and the geographical and meteorological conditions of the three air quality monitoring sites (i.e., BYH, CDH, and $\mathrm{NVH}$ ). This indicates that photolysis plays a minor role in altering the diagnostic binary ratios of PAHs in $\mathrm{PM}_{10}$. These findings are consistent with a previous report by Wortham et al. (1993), which suggested that in the absence of oxidising gaseous species, photodegradation is negligible for comparatively short irradiation times, e.g., $<2$ h for An, Fluo, Pyr, B[a]P, B [g,h,i]P, and B[b]F. As the sampling time of DPIMC was three hours, it is reasonable to interpret the "non-significant differences" for all the 
diagnostic binary ratios of PAHs as a consequence of comparatively low irradiation in the absence of oxidising gases.

\section{Inter-site comparison of coefficient of divergence (COD)}

One of the most challenging problems is to assess the degree to which site-specific conditions affect the PAH diagnostic binary ratios. If these ratios are influenced to some extent by source emission characteristics (e.g., vehicle types and driving cycle patterns), and environmental (e.g., geographic and building morphologies) and meteorological conditions (e.g., wind speed and direction), which are dependent variables of the sampling sites, careful consideration should be given to the interpretation of the data. Furthermore, it is difficult to assess the local and regional effects on the emission source strengths of the selected PAH diagnostic binary ratios. To evaluate the deviations in the temporal distributions of the selected PAH binary ratios at the seven air quality monitoring sites, the computation of the COD is recommended (Wilson et al., 2005; Limbeck et al., 2009), as explained below:

$$
C O D=\sqrt{\frac{1}{n} \sum_{i=1}^{n}\left(\frac{x_{i j}-\chi_{i k}}{\chi_{i j}+\chi_{i k}}\right)^{2}}
$$

where $\mathrm{x}_{\mathrm{ij}}$ indicates the $\mathrm{PAH}$ ratio for sampling event $\mathrm{i}$ at

Table 1. Comparison of Diagnostic Binary Ratios of Polycyclic Aromatic Hydrocarbons Collected During the Day and Night

\begin{tabular}{|c|c|c|c|c|c|}
\hline \multirow[t]{2}{*}{$\begin{array}{l}\text { Sampling Site } \\
\text { Sampling Period } \\
\text { Sampling Time }\end{array}$} & \multicolumn{5}{|c|}{$\begin{array}{l}\text { Bangkok } \\
\text { Feb-08 }\end{array}$} \\
\hline & Avg. & Std. dev. & Avg. & Std. dev. ( & $\begin{array}{l}\mathrm{t}-\text { Test } \\
(\mathrm{p}<0.05)\end{array}$ \\
\hline $\mathrm{An} /(\mathrm{An}+\mathrm{Phe})$ & 0.604 & 0.523 & 0.576 & 0.306 & NS \\
\hline Fluo/(Fluo + Pyr) & 0.507 & 0.062 & 0.483 & 0.196 & NS \\
\hline $\mathrm{B}[\mathrm{a}] \mathrm{A} /(\mathrm{B}[\mathrm{a}] \mathrm{A}+\mathrm{Chry})$ & 0.38 & 0.184 & 0.465 & 0.208 & NS \\
\hline $\mathrm{B}[\mathrm{a}] \mathrm{P} /(\mathrm{B}[\mathrm{a}] \mathrm{P}+\mathrm{B}[\mathrm{e}] \mathrm{P})$ & 0.4 & 0.129 & 0.518 & 0.208 & NS \\
\hline Ind/(Ind+B[g,h,i]P) & 0.411 & 0.235 & 0.358 & 0.246 & NS \\
\hline $\mathrm{B}[\mathrm{k}] \mathrm{F} / \mathrm{Ind}$ & 0.502 & 0.324 & 0.34 & 0.303 & NS \\
\hline \multirow[t]{2}{*}{$\begin{array}{l}\text { Sampling Site } \\
\text { Sampling Period } \\
\text { Sampling Time }\end{array}$} & \multicolumn{5}{|c|}{$\begin{array}{l}\text { Chiang-Mai } \\
\text { Feb-08 }\end{array}$} \\
\hline & Avg. & $\overline{\text { Std. dev. }}$ & $\overline{\text { Avg. }}$ & $\overline{\text { Std. dev. }}$ & $<0.05)$ \\
\hline$\overline{\mathrm{An} /(\mathrm{An}+\mathrm{Phe})}$ & 0.127 & 0.0608 & 0.0933 & 0.00334 & NS \\
\hline Fluo/(Fluo + Pyr) & 0.39 & 0.0658 & 0.413 & 0.0272 & NS \\
\hline $\mathrm{B}[\mathrm{a}] \mathrm{A} /(\mathrm{B}[\mathrm{a}] \mathrm{A}+\mathrm{Chry})$ & 0.421 & 0.0868 & 0.433 & 0.0614 & NS \\
\hline $\mathrm{B}[\mathrm{a}] \mathrm{P} /(\mathrm{B}[\mathrm{a}] \mathrm{P}+\mathrm{B}[\mathrm{e}] \mathrm{P})$ & 0.408 & 0.0648 & 0.466 & 0.0886 & NS \\
\hline Ind/(Ind+B[g,h,i]P) & 0.639 & 0.181 & 0.615 & 0.165 & NS \\
\hline $\mathrm{B}[\mathrm{k}] \mathrm{F} / \mathrm{Ind}$ & 0.143 & 0.0463 & 0.149 & 0.0309 & NS \\
\hline \multirow{3}{*}{$\begin{array}{l}\text { Sampling Site } \\
\text { Sampling Period } \\
\text { Sampling Time }\end{array}$} & \multicolumn{5}{|c|}{$\begin{array}{l}\text { Hat-Yai } \\
\text { Dec-07 }\end{array}$} \\
\hline & \multicolumn{2}{|c|}{ Day } & \multicolumn{2}{|c|}{ Night } & t-Test \\
\hline & $\overline{\text { Avg. }}$ & $\overline{\text { Std. dev. }}$ & Avg. & $\overline{\text { Std. dev. }}$ (1) & $\mathrm{p}<0.05)$ \\
\hline $\mathrm{An} /(\mathrm{An}+\mathrm{Phe})$ & 0.35 & 0.201 & 0.41 & 0.202 & NS \\
\hline Fluo/(Fluo + Pyr) & 0.121 & 0.0884 & 0.217 & 0.118 & NS \\
\hline $\mathrm{B}[\mathrm{a}] \mathrm{A} /(\mathrm{B}[\mathrm{a}] \mathrm{A}+\mathrm{Chry})$ & 0.37 & 0.0404 & 0.358 & 0.0409 & NS \\
\hline $\mathrm{B}[\mathrm{a}] \mathrm{P} /(\mathrm{B}[\mathrm{a}] \mathrm{P}+\mathrm{B}[\mathrm{e}] \mathrm{P})$ & 0.544 & 0.0527 & 0.481 & 0.0737 & NS \\
\hline Ind/(Ind+B $[\mathrm{g}, \mathrm{h}, \mathrm{i}] \mathrm{P})$ & 0.487 & 0.0967 & 0.452 & 0.131 & NS \\
\hline $\mathrm{B}[\mathrm{k}] \mathrm{F} / \mathrm{Ind}$ & 0.199 & 0.0621 & 0.329 & 0.198 & NS \\
\hline
\end{tabular}

sampling site $\mathrm{j}$, xik is the PAH ratio for the identical event $\mathrm{i}$ at sampling site $\mathrm{k}$, and $\mathrm{n}$ is the number of total sampling events. It is crucial to stress that both short- and long-term observations can be adapted to the principle of employing the COD because of the self-normalising characteristics of the process (Wongphatarakul et al., 1998). If the COD value approaches zero, it can be inferred that strong affinity exists between the emission sources of the two sampling sites. Conversely, if the COD value approaches one, it suggests divergence between the emission sources of the two investigated air sampling stations.

As displayed in Table 2, the average value of An/(An + Phe $)$ is three times more significant $(p<0.001)$ than Fluo/(Fluo + Pyr). This reflects greater divergence in the spatial distribution of An/(An + Phe), which can be attributed to several causes. According to a previous study, the overall rate of photodegradation of irradiated 2-3-ring PAHs on soot particles is affected by fast photolysis and fast diffusion kinetics, while that of PAHs with 4 or more rings is evidently governed by either the combination of slow photolysis and slow diffusion kinetics, or by extremely slow diffusion kinetics alone (Kim et al., 2013). Therefore, the comparatively high COD value of An/ $(\mathrm{An}+\mathrm{Phe})$ reflects the greater fragility of these LMW congeners in comparison with those of Fluo and Pyr. It is also interesting to note that the three highest COD values of $\mathrm{An} /(\mathrm{An}+\mathrm{Phe})$ were observed for the combinations of KHA-BHS (0.495), CPB-BHS (0.465), and SPS-BHS $(0.455)$, as illustrated in Table 2.

As the KHA and CPB sampling sites are representative of traffic routes and the BHS site is situated in a residential area, the comparatively high COD values observed for these two combinations might simply reflect differences in the characteristics of the emission sources between the two sites. Furthermore, a study by Valavanidis et al. (2009) found that ozone from vehicular emissions was responsible for the generation of hydroxyl radicals, which are frequently referred to as the "detergent" of the troposphere because they react with various types of air pollutants including PAHs (Jariyasopit et al., 2014). Heterogeneous reactions of $\mathrm{PM}_{10}$-bound PAHs with $\mathrm{NO}_{3} / \mathrm{N}_{2} \mathrm{O}_{5}, \mathrm{OH}$ radicals, and $\mathrm{O}_{3}$ released from traffic exhausts can also dramatically reduce the atmospheric concentrations of PAHs (Jariyasopit et al., 2014) and thus, they might alter the diagnostic binary ratios of $\mathrm{An} /(\mathrm{An}$ + Phe) at KHA and CPB. Conversely, the three lowest COD values for $\mathrm{An} /(\mathrm{An}+\mathrm{Phe})$ were observed for the combinations of TPS-NWS (0.117), DHA-TPS (0.139), and DHA-NWS (0.187). Because these three air quality monitoring sites are all categorised as representative of an urban residential background, it is reasonable to ascribe the relatively low COD values to the strong similarities in the temporal variation of $\mathrm{An} /(\mathrm{An}+\mathrm{Phe})$ between the two sampling sites.

\section{Influence of traffic emissions on PAH diagnostic binary ratios}

The impact of traffic emissions on PAH diagnostic binary ratios has been investigated as part of the CMPIA project at two monitoring sites: PTOS and ICZOS. As the PTOS is located only a few hundreds of metres from 
Assessment of Reliability when Using Diagnostic Binary Ratios of Polycyclic Aromatic Hydrocarbons in Ambient Air PM10

a highway, it is reasonable to ignore contributions to the PAH aerosol concentrations caused by non-traffic sources and other atmospheric chemical and/or physical processes. However, it is crucial to stress that the ICZOS is situated within the IRPC Complex Zone. Thus, differences in the $\mathrm{PM}_{10}$-bounded PAH concentrations between the PTOS and ICZOS can only be attributed to vehicular exhausts. If the effects of traffic emissions are larger than those of industrial combustion and other potential industrial sources, some significant differences of PAH diagnostic binary ratios between the two observatory sties should be observed. Conversely, if the influence of traffic emissions is minor, then no significant differences in the binary ratios should be detected.

The t-test statistic can be used to determine whether

Table 2. Coefficient of Divergence for An/(An + Phe $)$ and Fluo/(Fluo + Pyr) Measured at seven Air quality monitoring sites in Bangkok

\begin{tabular}{lcc}
\hline & An/(An + Phe $)$ & Fluo/(Fluo + Pyr) \\
\hline CPB-DHA & 0.35 & 0.084 \\
CPB-TPS & 0.338 & 0.141 \\
CPB-SPS & 0.267 & 0.119 \\
CPB-KHA & 0.315 & 0.176 \\
CPB-NWS & 0.269 & 0.168 \\
CPB-BHS & 0.465 & 0.174 \\
DHA-TPS & 0.139 & 0.143 \\
DHA-SPS & 0.339 & 0.139 \\
DHA-KHA & 0.382 & 0.199 \\
DHA-NWS & 0.187 & 0.171 \\
DHA-BHS & 0.305 & 0.193 \\
TPS-SPS & 0.322 & 0.104 \\
TPS-KHA & 0.345 & 0.157 \\
TPS-NWS & 0.117 & 0.086 \\
TPS-BHS & 0.295 & 0.107 \\
SPS-KHA & 0.328 & 0.15 \\
SPS-NWS & 0.293 & 0.135 \\
SPS-BHS & 0.455 & 0.177 \\
KHA-NWS & 0.305 & 0.161 \\
KHA-BHS & 0.495 & 0.158 \\
NWS-BHS & 0.323 & 0.132 \\
Avg. & 0.316 & 0.146 \\
Std. dev. & 0.093 & 0.032 \\
\hline Not KHA $-K 15 c h$
\end{tabular}

Note: KHA - Klongchan National Housing Authority, NWS Nonsreewitayakom High School, SPS - Singharaj Pitayakhom High School, TPS - Thonburi Power Substation, CPB - Chokchai 4 Police Box, DHA - Dindang National Housing Authority, and BHS Badindecha High School

Table 3. Statistical Descriptions and t-Test Results for Diagnostic Binary ratios of PM10-bounded Polycyclic Aromatic Hydrocarbons Collected at the Pluakgate Temple Observatory Station (PTOS) and IRPC Complex Zone Observatory Station (ICZOS)

\begin{tabular}{lccccc}
\hline & \multicolumn{2}{c}{ PTOS } & \multicolumn{2}{c}{ ICZOS } \\
& Avg. & Std. dev. & \multicolumn{4}{c}{ Avg. } & Std. dev. t-Test \\
\hline An/(An + Phe) & 0.223 & 0.207 & 0.234 & 0.214 & NS \\
Fluo/(Fluo + Pyr) & 0.405 & 0.156 & 0.383 & 0.124 & NS \\
B[a]A/(B[a]A+Chry) & 0.434 & 0.187 & 0.42 & 0.191 & NS \\
B[a]P/(B[a]P+B[e]P) & 0.394 & 0.245 & 0.371 & 0.248 & NS \\
Ind/(Ind+B[g,h,i]P) & 0.432 & 0.189 & 0.389 & 0.198 & NS \\
B[k]F/Ind & 1.763 & 1.959 & 1.863 & 1.59 & NS \\
\hline
\end{tabular}

*NS means not significant two independent populations have different mean values on some measure. Thus, the average values of the PAH diagnostic binary ratios collected at the two monitoring sites were calculated and compared. As can be clearly seen from Table 3, there is no significant difference ( $\mathrm{p}$ $<0.001)$ in any of the six PAH diagnostic binary ratios between the two monitoring sites. As the CMPIA project covered the measurement of particulate PAHs from 2010 to 2013, the comparatively long four-year observation period underlines the reliability of using PAH ratios as alternative chemical tracers for source categorisation. It is also crucial to note that these two monitoring sites are located within the coastal region of Rayong Province, i.e., an area predominantly governed by both sea and land breezes. These prevailing winds could have been responsible for the comparatively homogeneous air mass over the monitoring area, which led to the lack of significant differences in PAH binary ratios between the two stations. Another explanation for these findings is the extremely low concentrations of PAHs observed in this coastal area in comparison with other cities around the world (Pongpiachan et al., 2015b). As discussed in the previous section, oxidising gaseous species from vehicular exhausts can play an important role in reducing some LMW PAHs, which could be responsible for the alteration of the diagnostic binary ratios in areas with heavy traffic congestion. In addition, the application of PAH ratios only functions properly if the air quality observations are conducted in a clean air environment with relatively low concentrations of oxidising gaseous species.

In conclusion, the conclusions of this study are drawn based on the evidence that the photolysis process and vehicular exhausts play minor roles in altering PAH ratios. For application of the diagnostic binary ratios in areas of heavy traffic congestion, particularly careful attention should be given the data interpretation because $\mathrm{NO}_{3} / \mathrm{N}_{2} \mathrm{O}_{5}$, $\mathrm{OH}$ radicals, and $\mathrm{O} 3$ from vehicles can cause dramatic fluctuations of the PAH ratios. While the Fluo/(Fluo + Pyr) ratios did show some small inter-site differences with comparatively low COD values, careful examination of the binary ratios of $\mathrm{An} /(\mathrm{An}+\mathrm{Phe})$ is crucial for a more precise elucidation of source categorisation for $\mathrm{PM}_{10}{ }^{-}$ bounded PAHs.

\section{Acknowledgements}

This work was performed with the approval of the National Institute of Development Administration (NIDA), Thailand. The author acknowledges the research staff of the Pollution Control Department (PCD), Ministry of Natural Resources and Environment (MNRE), Thailand for its contributions to the field sampling and some laboratory work.

\section{References}

Alam MS, Delgado-Saborit JM, Stark C, et al (2013). Using atmospheric measurements of $\mathrm{PAH}$ and quinone compounds at roadside and Urban background sites to assess sources and reactivity. Atmos Environ, 77, 24-35.

Annamalai J, Namasivayam V (2015). Endocrine disrupting 
chemicals in the atmosphere: their effects on humans and wildlife. Environ Int , 76, 78-97.

Caldwell MM, Flint SD (1994). Stratospheric ozone reduction, Solar UV-B radiation and terrestrial ecosystems. Climatic Change, 28, 375-94.

Crépeaux G, Kremarik PB, Sikhayeva N, et al (2012). Late Effects of a Perinatal Exposure to a 16 PAH Mixture: increase of anxiety-related behaviours and decrease of regional brain metabolism in adult male rats. Toxicol Lett, 211, 105-13.

Dachs J, Eisenreich SJ (2000). Adsorption onto aerosol soot carbon dominates gas-particle partitioning of polycyclic aromatic hydrocarbons. Environ Sci Technol, 34, 3690-7.

Gao B, Wang XM, Zhao XY, et al (2015). Source apportionment of atmospheric PAHs and their toxicity using PMF: impact of Gas/Particle partitioning. Atmos Environ, 103, 114-20.

Gogou A, Stratigakis N, Kanakidou M, et al (1996). Organic aerosol in eastern mediterranean: component source reconciliation by using molecular markers and atmospheric back trajectories. Org Geochem, 25, 79-96.

Hanedar A, Alp K, Kaynak B, et al (2011). Concentrations and Sources of PAHs at Three Stations in Istanbul, Turkey. Atmos Res, 99, 391-9.

Jang E, Alam MS, Harrison RM (2013). Source apportionment of polycyclic aromatic hydrocarbons in urban air using positive matrix factorization and spatial distribution analysis. Atmos Environ, 79, 271-85.

Jariyasopit N, Zimmermann K, Schrlau J, et al (2014). Heterogeneous Reactions of Particulate Matter-Bound PAHs and NPAHs with $\mathrm{NO}_{3} / \mathrm{N}_{2} \mathrm{O}_{5}$, OH Radicals, and $\mathrm{O}_{3}$ under simulated long-range atmospheric transport conditions: reactivity and mutagenicity. Environ Sci Technol, 48, 10, 155-64.

Kim D, Young TM, Anastasio C (2013). Phototransformation rate constants of PAHs associated with soot particles. Sci Total Environ, 443, 896-903.

Limbeck A, Handler M, Puls C, et al (2009). Impact of mineral components and selected trace metals on ambient $\mathrm{PM}_{10}$ concentrations. Atmos Environ, 43, 530-8.

Liu J, Li J, Lin T, et al (2013). Diurnal and nocturnal variations of PAHs in the Lhasa atmosphere, tibetan plateau: implication for local sources and the impact of atmospheric degradation processing. Atmos Res, 124, 34-43.

Moorthy B, Chu C, Carlin DJ (2015). Polycyclic aromatic hydrocarbons: from metabolism to lung cancer. Toxicol Sci, 145, 5-15.

Müller AK, Farombi EO, Møller P, et al (2004). DNA damage in lung after oral exposure to diesel exhaust particles in big blue ${ }^{\circledR}$ rats. Mutat Res-Fund $\mathrm{Mol}$ M, 550, 123-32.

Niu J, Sun P, Schramm KW (2007). Photolysis of Polycyclic Aromatic Hydrocarbons Associated with Fly Ash Particles under Simulated Sunlight Irradiation. J Photoc Photobio A, 186, 93-8.

Odabasi M, Cetin E, Sofuoglu A (2006). Determination of octanol-air partition coefficients and super-cooled liquid Vapor Pressures of PAHs as a function of temperature: application to gas-particle partitioning in an urban atmosphere. Atmos Environ, 40, 6615-25.

Ohura T, Horii Y, Kojima M, et al (2013). Diurnal variability of chlorinated polycyclic aromatic hydrocarbons in Urban Air, Japan. Atmos Environ, 81, 84-91.

Pongpiachan S, Bualert S, Sompongchaiyakul P, et al (2009). Factors affecting sensitivity and stability of polycyclic aromatic hydrocarbons. Anal Lett, 42, 2106-30.

Pongpiachan S (2010). Atmospheric lifetimes and traveling distances of airborne carcinogenic polycyclic aromatic hydrocarbons. Chinese. J Clinic (Electronic Edition), 16. (http://journal.shouxi.net/qikan/articledes.php?id=537551). Pongpiachan S, Ho KF, Lee SC (2010). A Study of Gas-Particle Partitioning of PAH According to Adsorptive Models and Season. In Air Pollution XVIII, WIT press, pp. 37-48. ISBN: 978-1-84564-450-5, ISSN (Online): 1743-3541, ISSN (Print): 1746-448X, June 2010. (Conference Book)

Pongpiachan S (2013a). Vertical distribution and potential risk of particulate polycyclic aromatic hydrocarbons in high buildings of Bangkok, Thailand. Asian Pac J Cancer Prev, 14, 1865-77.

Pongpiachan S (2013b). Diurnal variation, vertical distribution and source apportionment of carcinogenic polycyclic aromatic hydrocarbons (PAHs) in Chiang-Mai, Thailand. Asian Pac J Cancer Prev, 14, 1851-63.

Pongpiachan S, Choochuay C, Hattayanone M, et al (2013a). Temporal and spatial distribution of particulate carcinogens and mutagens in bangkok, Thailand. Asian Pac J Cancer Prev, 14, 1879-87.

Pongpiachan S, Ho KF, Cao J (2013b). Estimation of gas-particle partitioning coefficients $(\mathrm{kp})$ of carcinogenic polycyclic aromatic hydrocarbons by carbonaceous aerosols collected at chiang-mai, Bangkok and Hat-Yai, Thailand. Asian Pac J Cancer Prev, 14, 3369-84.

Pongpiachan S, Tipmanee D, Deelaman W, et al (2013c). Risk assessment of the presence of polycyclic aromatic hydrocarbons (PAHs) in coastal areas of Thailand affected by the 2004 Tsunami. Mar Pollut Bull, 76, 370-8.

Pongpiachan S (2014). Application of binary diagnostic ratios of polycyclic aromatic hydrocarbons for identification of tsunami 2004 backwash sediments in khao lak, Thailand, Scientific World J, 485068, 14.

Pongpiachan S (2015). A preliminary study of using polycyclic aromatic hydrocarbons as chemical tracers for traceability in soybean products. Food Control, 47, 392-400.

Pongpiachan S, Tipmanee D, Khumsup C, et al (2015a). Assessing Risks to Adults and Preschool Children Posed by PM2.5-bound polycyclic aromatic hydrocarbons (pahs) during a biomass burning episode in northern Thailand. Sci Total Environ, 508, 435-44.

Pongpiachan S, Hattayanone M, Choochuay C, et al (2015b). Enhanced $\mathrm{PM}_{10}$ Bounded PAHs from shipping emissions. Atmos Environ, 108, 13-9.

Ringuet J, Albinet A, Garziandia EL, et al (2012a). Reactivity of polycyclic aromatic compounds (PAHs, NPAHs and OPAHs) adsorbed on natural aerosol particles exposed to atmospheric oxidants. Atmos Environ, 61, 15-22.

Ringuet J, Albinet A, Garziandia EL, et al (2012b). Diurnal/ nocturnal concentrations and sources of particulate-bound PAHs, OPAHs, and NPAHs at traffic and suburban sites in the region of Paris (France). Sci Total Environ, 437, 297-305.

SrAm RJ, BinkovA B, Rossner P, et al (1999). Adverse Reproductive Outcomes from Exposure to Environmental Mutagens. Mutat Res-Fund Mol M, 428, 203-15.

Tipmanee D, Deelaman W, Pongpiachan S, et al (2012). Using polycyclic aromatic hydrocarbons (PAHs) as a chemical proxy to indicate tsunami 2004 backwash in khao lak coastal area, Thailand. Nat Hazards Earth Syst Sci, 12, 1441-51.

US-EPA(1999). Compendium of Methods for the Determination of Inorganic Compounds in Ambient Air. Compendium method IO-2.2. Sampling of Ambient Air for $\mathrm{PM}_{10}$ Using an Andersen Dichotomous Sampler. EPA/625/R-96/010a. Available from: http://www.epa.gov/ttnamti1/files/ambient/ inorganic/mthd-2-2.pdf.

Valavanidis A, Loridas S, Vlahogianni T, et al (2009). Influence of ozone on traffic-related particulate matter on the generation of hydroxyl radicals through a heterogeneous synergistic effect. J Hazard Mater, 162, 886-92. 
Venkatachalam S, Kuppusamy P, Kuppusamy B, et al (2014).

The potency of essential nutrient taurine on boosting the antioxidant status and chemopreventive effect against benzo(a)pyrene-induced experimental lung cancer. Biomed Prev Nutr, 4, 251-5.

Wang D, Chen J, Xu Z, et al (2005). Disappearance of polycyclic aromatic hydrocarbons sorbed on surfaces of pine [pinua thunbergii] needles under irradiation of sunlight: volatilization and photolysis. Atmos Environ, 39, 4583-91.

Wang D, Li Y, Yang M, et al (2008). Decomposition of polycyclic aromatic hydrocarbons in atmospheric aqueous droplets through sulfate anion radicals: an experimental and theoretical study. Sci Total Environ, 393, 64-71.

Wang Z, Na G, Ma X, et al (2013). Occurrence and gas/particle partitioning of PAHs in the atmosphere from the north pacific to the arctic ocean. Atmos Environ, 77, 640-6.

Wang Q, Xue Y (2015). Characterization of solid tumors induced by polycyclic aromatic hydrocarbons in mice. Med Sci Monit Basic Res, 21, 81-5.

Wilson JG, Kingham S, Pearce J, et al (2005). A review of intraurban variations in particulate air pollution: implications for epidemiological research. Atmos Environ, 39, 6444-62.

Wongphatarakul V, Friedlander SK, Pinto JP (1998). A comparative study of PM2.5 ambient aerosol chemical databases. Environ Sci Technol, 32, 3926-34.

Wortham H, Nguyen EB, Masclet P (1993). Study of heterogeneous reactions of polycyclic aromatic hydrocarbons I: Weakening of PAH-support bonds under photonic irradiation. Sci Total Environ, 128, 1-11.

Zhang Y, Shu J, Liu C, et al (2013). Heterogeneous Reaction of Particle-Associated Triphenylene with NO3 Radicals. Atmos Environ, 68, 114-9. 